\title{
Netrophil-Lymphocyte Ratio (NLR) In Covid 19 Patients With And Without Comorbids At Haji Adam Malik Medan Hospital
}

\author{
Refnol Hidayat ${ }^{1}$, Achsanuddin Hanafie ${ }^{2}$, Asmin Lubis ${ }^{2}$ \\ ${ }^{1}$ Resident of Anesthesiology and Intensive Therapy, Faculty of Medicine, Universitas Sumatera Utara, Medan, Indonesia \\ ${ }^{2}$ Department of Anesthesiology and Intensive Therapy, Faculty of Medicine, Universitas Sumatera Utara, Medan, Indonesia \\ DOI: 10.29322/IJSRP.11.11.2021.p11944 \\ http://dx.doi.org/10.29322/IJSRP.11.11.2021.p11944
}

\begin{abstract}
Background: The neutrophil-lymphocyte ratio is one indicator of a systemic inflammatory response that is widely used as a determinant of the prognosis of patients with viral pneumonia. An increased neutrophil-lymphocyte ratio may reflect an increased inflammatory process and may be associated with a poor prognosis. The increased neutrophil-lymphocyte ratio was significantly associated with the severity of the disease. Increased neutrophil-lymphocyte ratio can be considered independent biomarkers in indicating poor outcomes.
\end{abstract}

Purpose: This study aims to find out the difference in netrophil lymphocyte levels ratio in covid 19 patients with comorbidities and without comorbidity in H. Adam Malik General Hospital Medan.

Method: Retrospective analytical research where researchers use secondary data obtained from medical records at Haji Adam Malik Medan Hospital from June 2020 to May 2021 to find out the description of Netrophil-Lymphocyte Ratio (NLR) levels in covid 19 patients with comorbid and non-comorbid in H. Adam Malik General Hospital Medan. The sampling method uses the total sampling method, where patients diagnosed with COVID-19 are confirmed from June 2021 to May 2021.

Results: The sample obtained by 1098 patients with COVID-19 diagnoses confirmed PCR $(+)$ proportion of male sex amounted to $478(43.6 \%)$ samples and women by $620(56.4 \%)$. Proposed patients without comorbidity are smaller compared to comorbidities by $770(70.1 \%): 328(29.9 \%)$. The average age of the study subjects was $47 \pm 16.97$. Neutrophil average levels in patients was $71.21 \pm 17.24$, lymphocyte levels were $18.88 \pm 13.17$ and NLR $8.29 \pm 11.41$. While the average level of NLR value with comorbidities was $10.29 \pm 12.49$ and NLR level value without comorbidity was $7.44 \pm 10.82$ with the $p$ value of $<0.05$, which stastistically, there is a significant difference between variables.

Conclusion: There is a significant difference of that the NLR value of COVID-19 patients with comorbidities, whic is greater than NLR COVID-19 patients without comorbidity

Index Terms- Neutrophil lymphocyte ratio (NLR), Lymphocytes, Neutrophils, COVID-19

\section{INTRODUCTION}

$I^{n}$ n December 2019, the first case of mysterious pneumonia was reported in Wuhan, Hubei Province. The source of transmission is still unknown, but the first case was linked to a fish market in Wuhan. From December 18 to December 29 2019, there were five patients who were treated with Acute Respiratory Distress Syndrome (ARDS). From December 31, 2019 to January 3, 2020, the case increased rapidly, marked by the reported 44 cases. In less than a month, the disease has spread to other provinces in China, Thailand, Japan, and South Korea. Meanwhile, the first COVID19 was reported in Indonesia on March 2, 2020. The mortality rate for COVID-19 in Indonesia was 8.9\%.

The virus passed from person to person and has spread widely in China and more than 190 other countries and territories. On March 12, 2020, WHO declared COVID-19 as a pandemic. As of March 29 2020, there were 634,835 cases and 33,106 deaths worldwide. Meanwhile, in Indonesia, 1,528 cases have been confirmed positive for COVID-19 and 136 deaths.

Neutrophils are the main component of leukocytes that actively migrate to the immune system or organ. Neutrophils secrete large amounts of ROS (Reactive Oxygen Species) which induce damage to the cell's DNA and cause the virus to freely leave the cell. Then ADCC (Antibody- Dependent Cell-Mediated Cell) can directly kill the virus and trigger humoral immunity. Neutrophils can be triggered by viral-associated inflammatory factors, such as interleukin-6, interleukin-8, tumor necrosis factor, granulocyte colony stimulating factor, and interferon-gamma factor, which is produced by lymphocytes and endothelial cells. In addition, the human immune response caused by viruses is mainly dependent on lymphocytes, whereas systemic inflammation significantly suppresses cellular immunity, which significantly decreases CD4+ $\mathrm{T}$ lymphocyte levels and increases CD8+ suppressor $\mathrm{T}$ lymphocytes. Therefore, viral induced inflammation increases the neutrophil-lymphocyte ratio. An increase in the neutrophil-lymphocyte ratio triggers the progression of COVID19.

Early identification is needed to predict the condition of patients who are at risk for worsening symptoms to become more severe. Simple laboratory tests such as measurement of the neutrophil-lymphocyte ratio are known to be used as factors to determine the prognosis of patients in various clinical situations. 
An increase in the neutrophil-lymphocyte ratio is known to be associated with the severity of a disease and can be considered as an independent biomarker to indicate a poor outcome.

Neutrophil-lymphocyte ratio is one indicator of the presence of a systemic inflammatory response that is widely used as a determinant of the patients' prognosis with viral pneumonia. An increase of neutrophil-lymphocyte ratio may reflect an increased inflammatory process and may be associated with a poor prognosis. Increased neutrophil-lymphocyte ratio and age were significantly related to the severity of the disease. Increasing age and neutrophil-lymphocyte ratio can be considered as independent biomarkers in indicating poor outcome.

Based on the background and research references above, the researcher wishes to find out whether there is a difference in the levels of neutrophil to lymphocyte ratio in COVID-19 patients with and without comorbidities at RSUP. H. Adam Malik Medan.

\section{METHOD}

This study is a retrospective analytic study. This study aims to determine the description of the levels of NeutrophilLymphocyte Ratio (NLR) in Covid 19 patients with comorbid and without comorbidities in H. Adam Malik General Hospital Medan. Research done by using secondary data obtained from the medical record at Haji Adam Malik General Hospital Hospital from June 2020 to May 2021. The sampling technique was done by total sampling method with the study population was all patients diagnosed with covid 19 who were treated in the isolation room of the H. Adam Malik General Hospital, Medan. After obtaining approval from the Health Research Medical Committee, Faculty of Medicine, Universitas Sumatra Utara/ H. Adam Malik General Hospital Medan, based on the inclusion and exclusion criteria, the research sample was found to be 1098 samples. The data taken in the form of patient data, diagnosis, lymphocyte values, neutrophil values. After the required data has been collected, then the rechecked has been done for completeness before being tabulated and processed. Analysis using paired $\mathrm{T}$ test if the data is normally distributed. If the data is not normally distributed, the Wilcoxon test will be performed. Numerical data is shown in mean \pm SD (standard deviation), while categorical data is shown in sum (percentage). All data obtained were analyzed statistically.

\section{RESULT}

The study used secondary data obtained from the medical record at Haji Adam Malik General Hospital Medan from June 2020 to May 2021 to find out the description of NeutrophilLymphocyte Ratio (NLR) level in Covid 19 patients with and without comorbidities at the H. Adam Malik General Hospital Medan. The samples obtained were 1098 patients.

Based on Table 4.1, the proportion of male sample are 478 $(43.6 \%)$ samples and $620(56.4 \%)$ are female. The proportion of patients without comorbid is smaller than that of comorbid by 770 $(70.1 \%): 328(29.9 \%)$. The mean age of research subjects is $47 \pm$ 16.97. The average value of neutrophil levels in Covid patients was $71.21 \pm 17.24$, the value of lymphocyte levels was $18.88 \pm$ 13.17 and NLR $8.29 \pm 11.41$.

Based on the table above, the average NLR value with comorbidities is $10.29 \pm 12.49$ and the NLR level without comorbidity is $7.44 \pm 10.82$. The mean value of neutrophils with comorbidities was $15.38 \pm 11.55$ and without comorbidity $20.35 \pm$ 18.80. The mean value of lymphocytes with comorbidities was $74.26 \pm 79.85$ and without comorbidity $69.95 \pm 71.10$. Statistically, the $\mathrm{p}$ value $<0.05$ on the characteristics of neutrophils, lymphocytes and NLR, it can be concluded that the two variables are significantly different.

\section{CONCLUSION}

From the results of research that assesses the description of neutrophil lymphocyte ratio level in covid 19 patients with and without comorbid at H. Adam Malik General Hospital Medan, can be concluded that:

1. A significant difference was found that the NLR value in COVID-19 patients with comorbidities was greater than the NLR in COVID-19 patients without comorbidity.

2. The NLR mean value found in COVID-19 patients with comorbidities was $10.29 \pm 12.49$

3. The NLR mean value found in COVID-19 patients without comorbidity was $7.44 \pm 10.82$

\section{REFERENCES}

[1] Carlos, WG, Dela, CC, Cao, B., Pasnick, S., \& Jamil, S. (2020). Wuhan Novel (2019-nCoV) Coronavirus. American journal of respiratory and critical care medicine, 2001(4), P7. doi:10.1164/rccm.2014P7.

[2] Chen H, Guo J, Wang C, Luo F, Yu X, Zhang W, et al. Clinical characteristics and intrauterine vertical transmission potential of COVID-19 infection in nine pregnant women: a retrospective review of medical records. Lancet. 2020;395(10226):809-15 corona virus in the early stage. MedRxiv.doi:https://doi.org/10.1101/2020.02.10.20021584.

[3] Ministry of Health of the Republic of Indonesia. Information on Emerging Infections of the Indonesian Ministry of Health [Internet]. 2020 [updated 2020 March 30; cited 2020 March 31]. Available from: https://infectionemerging.kemkes.go.id/

[4] LaGunas-Rangel, FA.(2020). Neutrophil-to-lymphocyte ratio and Lymphocyte to C-Reactive Protein ratio in patients with severe coronavirus disease 2019 (COVID-19): A meta-analysis. Journal of medical virology. doi: https://doi.org/10.1002/jmv.25819

[5] Lee, JS, Kim, NY, Na, SH, Youn, YH, \& Shin, CS (2018). Reference values of neutrophil-lymphocyte ratio, lymphocyte-monocyte ratio, plateletlymphocyte ratio, and mean platelet volume in healthy adults in South Korea. Medicine, 97(26). doi:10.1097/MD.0000000000011138

[6] Li, Q., Guan, X., Wu, P., Wang, X., Zhou, L., Tong, Y., ... \& Xing, X. (2020) Early transmission dynamics in Wuhan, China, of novel coronavirusinfected pneumonia. New England Journal of Medicine. doi:10.1056/NEJMoa2001316.

[7] Tri Yulia Rini, Eternal Satriawan. 2020. Association of bacterial/viral infections with neutrophil-lymphocyte ratio, monocyte lymphocyte ratio, and platelet-lymphocyte ratio in patients presenting with fever. European Journal of Molecular \& Clinical Medicine

[8] Yang, AP, Liu, J., Tao, W., \& Li, HM (2020). The diagnostic and predictive role of NLR, dNLR and PLR in COVID-19 patients. International immunopharmacology, 106504. doi:https://doi.org/10.1016/j.intimp.2020. 106504.

[9] Yang, J., Zheng, Y., Gou, X., Pu, K., Chen, Z., Guo, Q., Ji, R., Wang, H., Wang, Y., \& Zhou, Y. (2020). Prevalence of comorbidities and its effects in coronavirus disease 2019 patients: A systematic review and meta-analysis.

This publication is licensed under Creative Commons Attribution CC BY. 
International Journal of Infectious Diseases, 94, 91-95. https://doi.org/10.1016/j.ijid.2020.03.017

\section{AUTHORS}

First Author - Refnol Hidayat, Resident of Anesthesiology and Intensive Therapy, Faculty of Medicine, Universitas Sumatera Utara, Medan, Indonesia, E-mail: refnolhidayat@yahoo.com
Second Author - Achsanuddin Hanafie, Department of Anesthesiology and Intensive Therapy, Faculty of Medicine, Universitas Sumatera Utara, Medan, Indonesia Third Author - Asmin Lubis, Department of Anesthesiology and Intensive Therapy, Faculty of Medicine, Universitas Sumatera Utara, Medan, Indonesia

Correspondence Author - Refnol Hidayat, refnolhidayat@yahoo.com, +62 812-6689-3245

Table 4.1 Overview of Characteristic Data

\begin{tabular}{ll}
\hline Characteristics & Subject $(\mathbf{n}=\mathbf{1 0 9 8})$ \\
\hline Age & $47 \pm 16.92$ \\
\hline Gender & \\
Male & $478(43.6 \%)$ \\
Female & $620(56.4 \%)$ \\
\hline Comorbid & $328(29.9 \%)$ \\
No Comorbid & $770(70.1 \%)$ \\
\hline
\end{tabular}

Table 4.2 Overview of NLR Values Based on Comorbid and Without Comorbid

\begin{tabular}{llll}
\hline Characteristics & Comorbid & No Comorbid & P value \\
\hline Neutrophils & $15.38 \pm 11.55$ & $20.35 \pm 18.80$ & 0.001 \\
Lymphocytes & $74.26 \pm 79.85$ & $69.95 \pm 71.10$ & 0.001 \\
NLR & $10.29 \pm 6.30$ & $7.45 \pm 3.77$ & 0.001 \\
\hline
\end{tabular}

*Wilcoxon 